\title{
Damping Parameters Identification of Cabin Suspension System for Heavy Duty Truck Based on Curve Fitting
}

\author{
Leilei Zhao, ${ }^{1,2}$ Changcheng Zhou, ${ }^{1}$ and Yuewei Yu' \\ ${ }^{1}$ School of Transportation and Vehicle Engineering, Shandong University of Technology, Zibo 255049, China \\ ${ }^{2}$ School of Automation, Beijing University of Posts and Telecommunications, Beijing 100876, China \\ Correspondence should be addressed to Changcheng Zhou; greatwall@sdut.edu.cn
}

Received 27 January 2016; Accepted 19 June 2016

Academic Editor: Nuno M. Maia

Copyright (c) 2016 Leilei Zhao et al. This is an open access article distributed under the Creative Commons Attribution License, which permits unrestricted use, distribution, and reproduction in any medium, provided the original work is properly cited.

\begin{abstract}
During the dynamic simulation of cabin system, the damping parameters values of cabin suspension are the key factors. In previous work, for obtaining all the parameters of the cabin system of trucks for long distance transport, a parameters identification model was built by minimizing the error of the root-mean-square acceleration between the tested and the measured. However, the identification precision is not high. In this paper, according to the real cabin system of a heavy duty truck for short distance transport, a 3-DOF model of cabin system was built. Based on curve fitting method, a new identification model for damping parameters was established. At last, the bench test was done and the comparisons were conducted among the tested values, the values identified by the method built in this work, and those obtained by the method built in previous work. The results show that the model built and the method proposed are feasible, and the identification precision is higher than the previous work.
\end{abstract}

\section{Introduction}

Heavy duty truck is widely used in the field of transportation [1]. The damping parameters of cabin suspension of trucks for short distance transport have significance for the improvement of ride comfort [2]. And the choice of damper characteristic is one key problem of cabin design. Prolonged exposure to occupational vibrations can lead to some diseases [3]. In order to improve ride comfort, the truck manufactures often develop different suspension types and structures for the cabin system, to isolate the truck driver from the vibrations as much as possible. And the full float cabin system is gradually used as the main type at present.

Numerous improvements have been made in recent years. Paper [4] analyzed possibilities and limitations with distributed damping in heavy vehicles and studied the power spectral density of the cab. Literature [5] studied tractor cabin's suspension parameters optimization by experimental and numerical methods. Hansson [6] made optimization of an agricultural tractor cab suspension using the evolution method. Paper [7] studied active cabin suspension in commercial trucks. Paper [8] provided a simplified method to design suspended cabins. Lovat et al. [9] simulated the dynamic characteristics of a fork lift truck travelling over an obstacle. From the efforts above, the damping parameters of cabin suspension are obtained by test. In order to improve ride comfort of trucks for short distance by simulation model, the damping parameters values of cabin suspension can be directly measured; however, the cost of bench test is very high. Some contributions can be found in literatures to obtain unknown parameters. For instance, Song and Liu [10] obtained the active magnetic bearings stiffness and damping from frequency characteristics of control system; Jin et al. [11] made dynamic parameter identification of hydrodynamic bearing-rotor system.

In our previous work [12], a coupling driver-seat-cab system model with 4 DOFs (degrees of freedom) according to the real cabin system of trucks for long distance transport was presented, and the damping parameters of "five-suspensions" were optimized to improve comfort. And, in the previous work, a parameters identification mathematical model was also built by minimizing the error of the RMS (root-meansquare) acceleration between the tested and the measured. By this mathematical model, all the parameters values for the 4-DOF dynamic model can be obtained. However, because the unknown parameters in the dynamic model are 


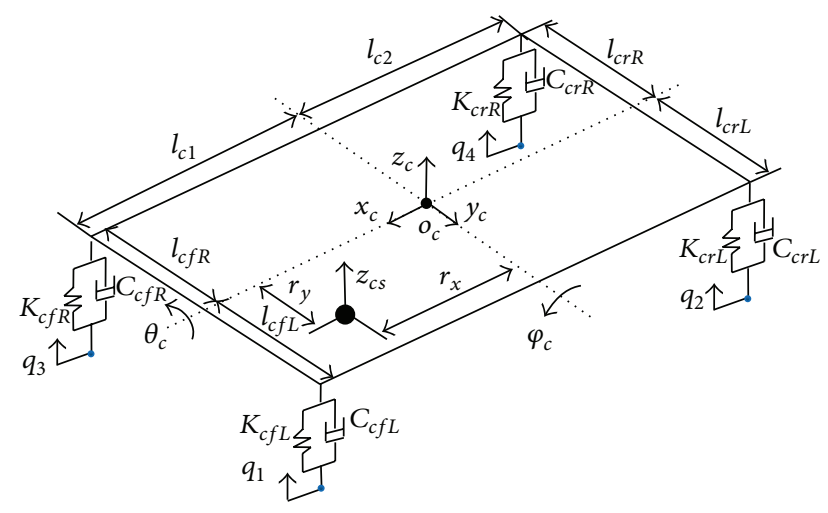

FIGURE 1: 3-DOF cabin system linear model.

too many, the accuracy of the parameters values identified is not high. It is one of the aims of our researches to improve the identification precision.

In this paper, the real cabin system of a heavy duty truck for short distance transport was studied. Contrary to trucks for long distance transport, the driver's seat of the heavy duty has no suspension system. To get more accurate damping parameters of the cabin system than previous work [12], based on curve fitting of acceleration power spectral density, the damping parameters identification model was established. In the end, the comparisons of the identification results were carried out to analyze the identification precision.

\section{Mathematical Model of the Cabin System}

2.1. Cabin System of Trucks for Short Distance Transport. According to the real cabin system of heavy duty truck for short distance transport, a 3-DOF cabin system linear model was built, as shown in Figure 1. The DOFs of the model are $z_{c}$, $\varphi_{c}$, and $\theta_{c}$, where $z_{c}$ is the translational degree of freedom of the cab along $z_{c}$-axis; $\varphi_{c}$ is the rotational degree of freedom of the cab around $y_{c}$-axis; $\theta_{c}$ is the rotational degree of freedom of the cab around $x_{c}$-axis.

The model assumptions in detail are as follows.

Assumption 1. Because the driver's seat is nonsuspended, thus, the seat and cabin are assumed to be one whole rigid body. Although both the seat and cabin may twist in reality, their elastic deformations could be ignored for this simplified model.

Assumption 2. The cabin is assumed to have three degrees of freedom $[8,12]$. Its actual motion is constrained by guiding mechanisms; its lateral displacement, yaw displacement, and longitudinal displacement are all very small.

Assumption 3. Both suspension stiffness and damping of the cabin are considered to be constant.

Assumption 4. Because the seat cushion is very hard, thus, the effect of its elastic deformation on the model is ignored.

The cabin coordinate system is established with its origin $o_{c}$ in the center of cabin system mass, defined as $x_{c}$-axis for horizontal (parallel to truck driving direction), $y_{c}$-axis for horizontal, and $z_{c}$-axis for vertical upward direction, as shown in Figure 1. Note that the cabin system mass includes the mass of the driver, seat, and the cabin.

2.2. The Governing Equations of Cab Motion. According to the 3-DOF cabin system model as shown in Figure 1, based on Lagrange modeling method, its vibration equations can be written as

$$
\begin{aligned}
{[-} & \left.K_{c f L}\left(z_{c f L}-q_{1}\right)\right]+\left[-C_{c f L}\left(\dot{z}_{c f L}-\dot{q}_{1}\right)\right] \\
& +\left[-K_{c f R}\left(z_{c f R}-q_{3}\right)\right]+\left[-C_{c f R}\left(\dot{z}_{c f R}-\dot{q}_{3}\right)\right] \\
& +\left[-K_{c r L}\left(z_{c r L}-q_{2}\right)\right]+\left[-C_{c r L}\left(\dot{z}_{c r L}-\dot{q}_{2}\right)\right] \\
& +\left[-K_{c r R}\left(z_{c r R}-q_{4}\right)\right]+\left[-C_{c r R}\left(\dot{z}_{c r R}-\dot{q}_{4}\right)\right] \\
& -m_{c} \ddot{z}_{c}=0 \\
- & {\left[K_{c f L}\left(z_{c f L}-q_{1}\right)+C_{c f L}\left(\dot{z}_{c f L}-\dot{q}_{1}\right)\right] l_{c f L} } \\
& +\left[K_{c f R}\left(z_{c f R}-q_{3}\right)+C_{c f R}\left(\dot{z}_{c f R}-\dot{q}_{3}\right)\right] l_{c f R} \\
& -\left[K_{c r L}\left(z_{c r L}-q_{2}\right)+C_{c r L}\left(\dot{z}_{c r L}-\dot{q}_{2}\right)\right] l_{c r L} \\
& +\left[K_{c r R}\left(z_{c r R}-q_{4}\right)+C_{c r R}\left(\dot{z}_{c r R}-\dot{q}_{4}\right)\right] l_{c r R} \\
& -I_{c x} \ddot{\theta}_{c}=0 \\
& \left.+K_{c f L}\left(z_{c f L}-q_{1}\right)+C_{c f L}\left(\dot{z}_{c f L}-\dot{q}_{1}\right)\right] l_{c 1} \\
& +\left[K_{c f R}\left(z_{c f R}-q_{3}\right)+C_{c f R}\left(\dot{z}_{c f R}-\dot{q}_{3}\right)\right] l_{c 1} \\
& -\left[K_{c r L}\left(z_{c r L}-\ddot{\varphi}_{c}\right)+C_{c r L}\left(\dot{z}_{c r L}-\dot{q}_{2}\right)\right] l_{c 2} \\
& \left.-\left[z_{c r R}-q_{4}\right)+C_{c r R}\left(\dot{z}_{c r R}-\dot{q}_{4}\right)\right] l_{c 2} \\
& -I_{c}
\end{aligned}
$$

where " $K$," " $C$," and " $l$ " represent stiffness, damping, and distance, respectively; the subscript " $c$ " represents cabin; the subscripts " $r$ " and " $f$ " represent rear and front, respectively; the subscripts " $R$ " and " $L$ " represent right and left, respectively; $m_{c}$ is the cabin system mass; $I_{c x}$ and $I_{c y}$ are the cabin system moment of inertia around the $x_{c}$-axis and $y_{c}$-axis, respectively; $q_{i}$ is the input of the $i$ th suspension of the cabin, where $i=1,2,3,4$.

In (1), the vertical displacement of the cabin at the respective suspension installation position can be obtained [12]; as follows.

The cabin vertical displacement at the installation position of its front-left suspension can be expressed as

$$
z_{c f L}=z_{c}-l_{c 1} \varphi_{c}+l_{c f L} \theta_{c} .
$$

The cabin vertical displacement at the installation position of its front-right suspension can be expressed as

$$
z_{c f R}=z_{c}-l_{c 1} \varphi_{c}-l_{c f R} \theta_{c}
$$


The cabin vertical displacement at the installation position of its rear-left suspension can be expressed as

$$
z_{c r L}=z_{c}+l_{c 2} \varphi_{c}+l_{c r L} \theta_{c}
$$

The cabin vertical displacement at the installation position of its rear-right suspension can be expressed as

$$
z_{c r R}=z_{c}+l_{c 2} \varphi_{c}-l_{c r R} \theta_{c}
$$

The cabin vertical displacement at the installation position of the seat can be expressed as

$$
z_{c s}=z_{c}-r_{x} \varphi_{c}+r_{y} \theta_{c}
$$

where $r_{j}$ is the distance between the installation position of the seat and origin $o_{c}$ in the $j_{c}$-axis direction, where $j=x, y$.

In particular, in this work, there is no special differential equation for the seat motion, and the seat motion only can be calculated by the geometrical relationship, (6).

\section{Damping Parameters Identification Model}

3.1. Minimization of the Particular Criterion and Constraints. In the previous work [12], a parameters identification mathematical model was built by minimizing the error $J_{I}$ of the root-mean-square acceleration between the tested and the measured. And the objective function $J_{I}$ can be expressed as

$$
\min \left\{J_{I}\right\}=\min \left\{\left(\sigma_{\ddot{z}_{s} \text { sim }}-\sigma_{\ddot{z}_{s} \text { test }}\right)^{2}\right\},
$$

where $\sigma_{\ddot{z}_{s} \text { sim }}$ and $\sigma_{\ddot{z}_{s} \text { test }}$ are the seat vertical RMS accelerations simulated and the tested, respectively. And the variables to be identified are mass parameters, the moment of inertia, the stiffness and damping parameters of seat suspension system, and cab suspension system, and the geometric parameters.

Although the values of the identified parameters are acceptable by (7), the variables to be identified are too many; thus, the accuracy of the values is not high. In order to get the damping parameters accurately, we try to use the curve fitting method to rebuild the objective function for identification and then realize the purpose of improving identification precision. Thus, in this work, based on curve fitting method, the objective function $J$ of parameters identification can be written as

$$
\begin{aligned}
& \min \left\{J\left(C_{c f L}, C_{c f R}, C_{c r L}, C_{c r R}\right)\right\} \\
& =\min \sum_{i=1}^{N}\left[\operatorname{PSD}_{\text {sim }}(i)-\operatorname{PSD}_{\text {test }}(i)\right]^{2},
\end{aligned}
$$

where $\mathrm{PSD}_{\text {sim }}$ and $\mathrm{PSD}_{\text {test }}$ represent the simulated seat vertical acceleration power spectral density and the tested, respectively; $i=1,2, \ldots, N$ in the analyzed frequency range; $C_{c f L}, C_{c f R}, C_{c r L}$, and $C_{c r R}$ are the variables to be identified.

From (6), it can be known that the seat vertical displacement is related to the cabin vertical displacement, the roll displacement, and the pitch displacement. That is to say, the seat vertical motion is affected synthetically by the cab vertical motion, the roll motion, and the pitch motion. Thus, for the objective function $J$ about the seat vertical acceleration, the synthetic factors have been taken into account. In essence, the particular criterion in this study is a comprehensive criterion for the $3 \mathrm{DOF}$ of the cabin system.

For the identified process, to simulate the real condition that the collision probability between the cabin and the chassis frame is within $0.135 \%$, the ratio of the standard deviation $\sigma\left(f_{d}\right)$ of the cabin suspension dynamic travel $f_{d}$ to the limited travel $\left[f_{d}\right]$ of the cabin suspension system must satisfy

$$
\frac{\sigma\left(f_{d}\right)}{\left[f_{d}\right]} \leq \frac{1}{3} .
$$

3.2. Data Collection for Identification. For the purpose of providing accurate input signals and output signal for the simulation model, the field measurement should be made.

Taking the truck to be analyzed as test object, four accelerometers should be installed on the frame at the respective installation position of cabin suspension, and an accelerometer should be installed on the seat pan. With the truck under the conditions of fully laden, most common road and speed, and by the test equipment, the vertical vibration accelerations should be tested for a period of time.

3.3. Signals Extraction for Simulation Model. The field tested signals of the truck to be analyzed are acceleration signals; however, the simulation model needs displacement signals as inputs. Thus, the tested signals should be integrated twice. Therefore, the tested signals should be processed as follows. Firstly, through the analysis of the raw data, relatively stationary acceleration excitations of cabin suspensions are extracted. Then, by frequency-domain integral method with minimum cut-off $0.5 \mathrm{~Hz}$ and maximum cut-off $80 \mathrm{~Hz}$, the displacement signals $q_{1} \sim q_{4}$ required by the Simulink model are obtained through double integrating of the acceleration signals, respectively. Simultaneously, the corresponding tested seat vertical acceleration signalshould be extracted.

\section{Damping Parameters Identification}

To demonstrate the effectiveness and correctness of the damping parameters identification method, case study is carried out in this section. For a heavy duty truck in this study, its drive type is $8 \times 4$, and its gross vehicle weight and load capacity are 42.5 and 60.0 ton, respectively. When the theory analysis of ride comfort for the cabin system of the truck is needed, all the damping parameters values of the cabin suspension system should be accurately obtained. The mechanical parameters except the damping parameters of cabin suspension have been obtained from the truck 
TABLE 1: The mechanical parameters of the cabin system.

\begin{tabular}{lc}
\hline Mechanical parameters & Values \\
\hline$K_{c f L}(\mathrm{~N} / \mathrm{m})$ & 43462 \\
$K_{c f R}(\mathrm{~N} / \mathrm{m})$ & 42351 \\
$K_{c r L}(\mathrm{~N} / \mathrm{m})$ & 32156 \\
$K_{c r R}(\mathrm{~N} / \mathrm{m})$ & 32593 \\
$m_{c}(\mathrm{~kg})$ & 721 \\
$I_{c x}\left(\mathrm{~kg} \cdot \mathrm{m}^{2}\right)$ & 813 \\
$I_{c y}\left(\mathrm{~kg} \cdot \mathrm{m}^{2}\right)$ & 764 \\
$l_{c f L}(\mathrm{~m})$ & 0.532 \\
$l_{c f R}(\mathrm{~m})$ & 0.521 \\
$l_{c r L}(\mathrm{~m})$ & 0.551 \\
$l_{c r R}(\mathrm{~m})$ & 0.542 \\
$l_{c 1}(\mathrm{~m})$ & 0.816 \\
$l_{c 2}(\mathrm{~m})$ & 0.867 \\
$r_{x}(\mathrm{~m})$ & 0.312 \\
$r_{y}(\mathrm{~m})$ & 0.210 \\
\hline
\end{tabular}

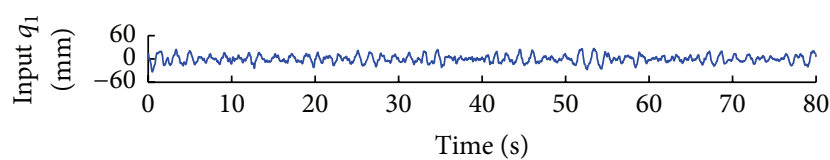

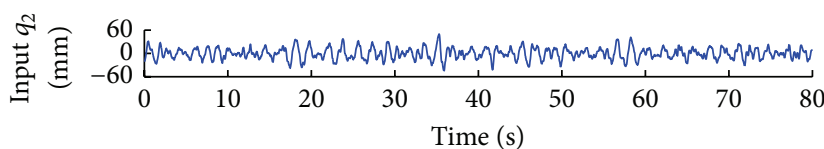

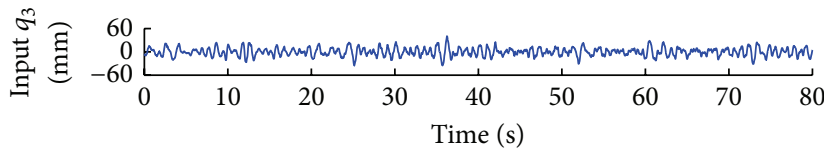
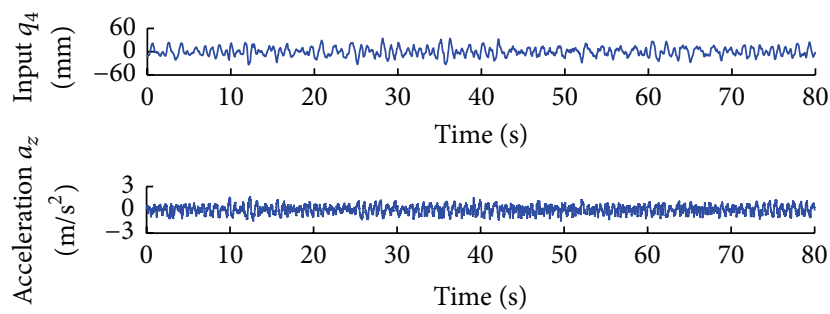

FIGURE 2: The tested signals $q_{1} \sim q_{4}$ and the tested seat vertical acceleration response $a_{z}$.

manufacturer's datasheets, as shown in Table 1. For each suspension in this study, the dynamic limited travel $\left[f_{d}\right]$ is $30.0 \mathrm{~mm}$.

4.1. Signals Collection and Processing. Using the truck to be analyzed as test object, according to the method mentioned in Sections 3.2 and 3.3, with the truck under fully laden conditions, on the highway at $70 \mathrm{~km} / \mathrm{h}$, the acceleration signals were tested. The sampling length was $200 \mathrm{~s}$ and the sampling frequency was $200 \mathrm{~Hz}$. The raw data were processed. The tested signals $q_{1} \sim q_{4}$ and the tested seat vertical acceleration response $a_{z}$ with length of $80 \mathrm{~s}$ were obtained as shown in Figure 2.
TABLE 2: Identification results of damping parameters.

\begin{tabular}{lc}
\hline Identification variables & Identification results $(\mathrm{N} \cdot \mathrm{s} / \mathrm{m})$ \\
\hline$C_{c f L}$ & 1512 \\
$C_{c f R}$ & 1520 \\
$C_{c r L}$ & 1618 \\
$C_{c r R}$ & 1621 \\
\hline
\end{tabular}

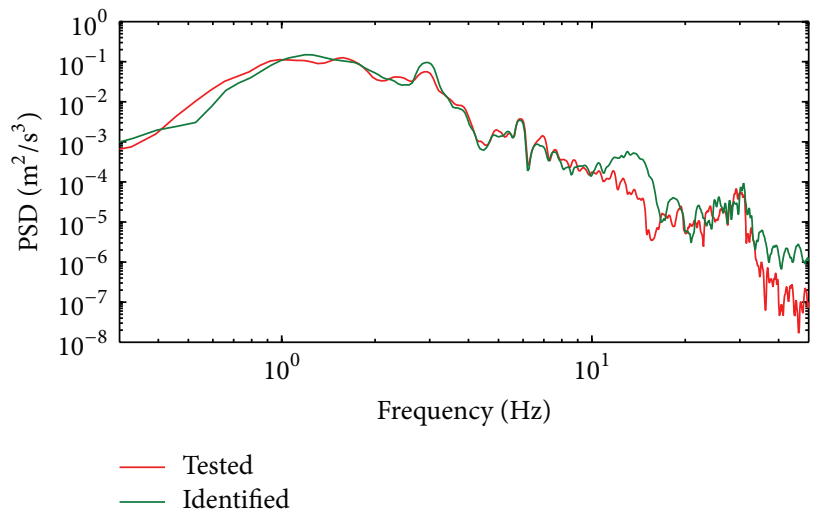

FIGURE 3: Comparison of the seat vertical acceleration PSD between the tested and identified.

4.2. Damping Parameters Identification of Cabin Suspension. According to the tested signals, by the Simulink model and the damping parameters identification program, the parameters identification was done and the results are shown in Table 2. Figure 3 presents a comparison of the seat vertical acceleration PSD (power spectral density) between the tested and identified.

From Figure 3, the identified PSD well coincides with the tested. The results show that the curve fitting method is feasible.

\section{Experimental Study and Results Comparison}

In order to verify the feasibility of the damping parameters identification method presented and the cabin system model established, the bench test was carried out and the comparisons were conducted among the tested values, the identified values using the method built in this work, and those using the method built in the previous work [12].

Four dampers of the cabin suspension system were tested in this study. The test was conducted by the multifunction hydraulic vibrating test equipment, as shown in Figure 4.

Each damper was reciprocated at a frequency of $1.67 \mathrm{~Hz}$ and an amplitude of $\pm 15.0 \mathrm{~mm}$ exerted by the equipment. Under this motion, the damping force at different velocities was measured. Using the analysis software to analyze test data, the damping parameters values of four dampers were obtained, respectively. The test results are shown in Table 3. Figure 5 provides a comparison of the identified 
TABLE 3: The identified values, the tested values of the damping parameters, and their comparisons.

\begin{tabular}{lccccc}
\hline \multirow{2}{*}{ Damping parameters } & \multirow{2}{*}{ Tested (N.s/m) } & \multicolumn{2}{c}{ This work } & \multicolumn{2}{c}{ Previous work [12] } \\
& & Identified value $(\mathrm{N} \cdot \mathrm{s} / \mathrm{m})$ & Relative deviation (\%) & Identified value (N·s/m) & Relative deviation (\%) \\
\hline$C_{c f L}$ & 1358 & 1512 & 10.2 & 1546 & 13.84 \\
$C_{c f R}$ & 1386 & 1520 & 9.7 & 1571 & 13.35 \\
$C_{c r L}$ & 1432 & 1618 & 13.0 & 1637 & 14.32 \\
$C_{c r R}$ & 1479 & 1621 & 9.6 & 1694 & 14.54 \\
\hline
\end{tabular}

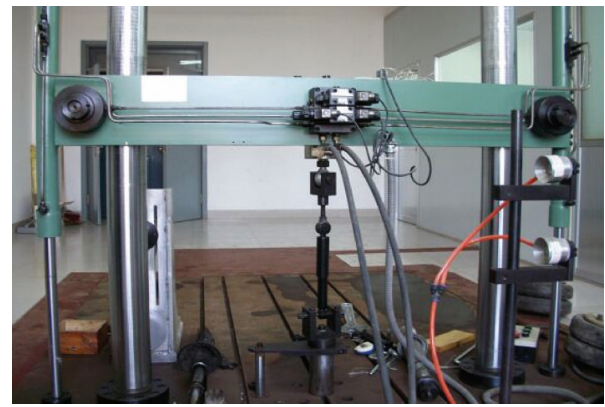

FIGURE 4: Experimental set-up and damping test.

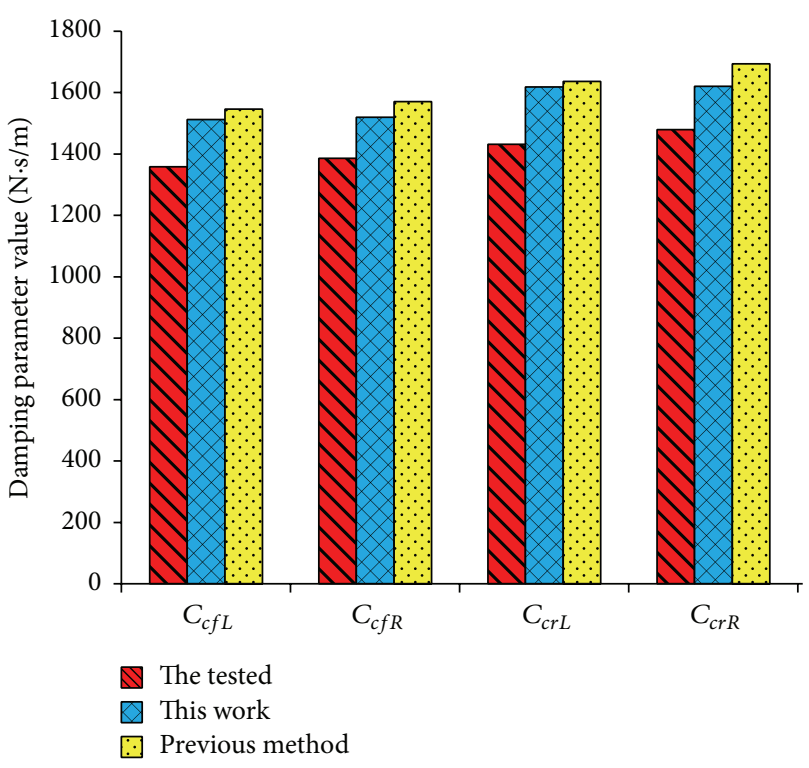

Figure 5: Comparison of the identified values.

values between this work and the previous work [12], which describes directly their discrepancies.

From Table 3, the absolute deviations of the damping parameters values between the tested and the identified by the identification method in this work are $154 \mathrm{~N} \cdot \mathrm{s} / \mathrm{m}, 134 \mathrm{~N} \cdot \mathrm{s} / \mathrm{m}$, $186 \mathrm{~N} \cdot \mathrm{s} / \mathrm{m}$, and $142 \mathrm{~N} \cdot \mathrm{s} / \mathrm{m}$, respectively; and the relative deviations are $10.2 \%, 9.7 \%, 13.0 \%$, and $9.6 \%$, respectively. The absolute deviations of the damping parameters values between the tested and the identified by the identification method in the previous work are $188 \mathrm{~N} \cdot \mathrm{s} / \mathrm{m}, 185 \mathrm{~N} \cdot \mathrm{s} / \mathrm{m}, 205 \mathrm{~N} \cdot \mathrm{s} / \mathrm{m}$, and $215 \mathrm{~N} \cdot \mathrm{s} / \mathrm{m}$, respectively; and the relative deviations are
$13.84 \%, 13.35 \%, 14.32 \%$, and $14.54 \%$, respectively. From Figure 5, using the method of parameters identification in previous work [12], the damping parameters values obtained are larger than those obtained by the identification method in this work, and the relative deviations are also larger.

According to the design requirements of damper for the cabin suspension, the design error of each damper itself is smaller than $\pm 15 \%$. Thus, the identified values for the two methods are acceptable. However, for the identified method based on curve fitting in this work, the identification precision is higher. It proves that the identification method presented is feasible.

\section{Conclusions}

According to the real cabin system of a heavy duty truck for short distance transport, a 3-DOF cabin system linear model was built. Based on curve fitting of acceleration power spectral density, its damping parameters identification mathematical model was established. By the test verification of damping parameters, the results show that the identification method is feasible.

By comparison, for the identified method based on curve fitting in this work, the identification precision is higher than that of the previous work. This work will be helpful in practical applications. For example, the acquisition method of damping parameters of cabin suspension system is more convenient and cost-effective than bench test, and it can substitute for the latter in reality. Moreover, it can also be used as the diagnosis fault method of the dampers for the cabin suspension, without dismantling the dampers from the cabin system.

In the following paper, the optimal damping match of the cabin suspension system will be discussed, and by building the nonlinear dynamic model of the cabin system, the more accurate damping characteristics of the cabin suspension system will be researched in detail.

\section{Competing Interests}

The authors declare that there are no competing interests regarding the publication of this paper.

\section{Acknowledgments}

This work is supported by the National Natural Science Foundation of China (51575325), the Nature Science Foundation 
of Shandong (ZR2013EEM007), and Key R \& D projects in Shandong Province (2015GGX105006).

\section{References}

[1] S. M. Polami, R. Reinhardt, M. Rethmeier, and A. Schmid, "Joint-site structure friction welding method as a tool for drive pinion light weighting in heavy-duty trucks," Journal of Materials Processing Technology, vol. 214, no. 9, pp. 1921-1927, 2014.

[2] D. Y. Chen, L. M. Wang, C. Z. Wang, L. K. Yuan, T. Y. Zhang, and Z. Z. Zhang, "Finite element based improvement of a light truck design to optimize crashworthiness," International Journal of Automotive Technology, vol. 16, no. 1, pp. 39-49, 2015.

[3] M. H. Pope, D. G. Wilder, and M. L. Magnusson, "A review of studies on seated whole body vibration and low back pain," Proceedings of the Institution of Mechanical Engineers, Part H, vol. 213, no. 6, pp. 435-446, 1999.

[4] P. Holen and B. Thorvald, "Possibilities and limitations with distributed damping in heavy vehicles," Vehicle System Dynamic Supplement, vol. 41, pp. 172-181, 2004.

[5] M. Zehsaz, M. H. Sadeghi, M. M. Ettefagh, and F. Shams, "Tractor cabin's passive suspension parameters optimization via experimental and numerical methods," Journal of Terramechanics, vol. 48, no. 6, pp. 439-450, 2011.

[6] P.-A. Hansson, "Optimization of agricultural tractor cab suspension using the evolution method," Computers and Electronics in Agriculture, vol. 12, no. 1, pp. 35-49, 1995.

[7] W.-J. Evers, I. Besselink, A. Teerhuis, A. Van Der Knaap, and H. Nijmeijer, "Controlling active cabin suspensions in commercial vehicles," in Proceedings of the American Control Conference (ACC '09), pp. 683-688, St. Louis, Mo, USA, June 2009.

[8] P. Lemerle, P. Boulanger, and R. Poirot, "A simplified method to design suspended cabs for counterbalance trucks," Journal of Sound and Vibration, vol. 253, no. 1, pp. 283-293, 2002.

[9] G. Lovat, P. Mistrot, P. Donati, P. Boulanger, and B. Schuler, "Simulation of the dynamic characteristics of a fork lift truck travelling over an obstacle," International Journal of Vehicle Design, vol. 4, no. 2-4, pp. 183-202, 1997.

[10] Z. Song and Y. Liu, "Dynamic parameter identification of hydrodynamic bearing-rotor system," Shock and Vibration, vol. 2015, Article ID 959568, 7 pages, 2015.

[11] C. W. Jin, Y. P. Xu, J. Zhou, and C. L. Cheng, "Active magnetic bearings stiffness and damping identification from frequency characteristics of control system," Shock and Vibration, vol. 2016, Article ID 1067506, 8 pages, 2016.

[12] L. L. Zhao, C. C. Zhou, Y. W. Yu, and F. X. Yang, "Hybrid modelling and damping collaborative optimisation of fivesuspensions for coupling driver-seat-cab system," Vehicle System Dynamics, vol. 54, no. 5, pp. 667-688, 2016. 


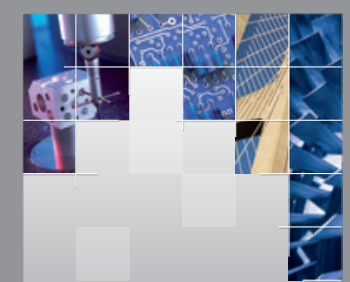

\section{Enfincering}
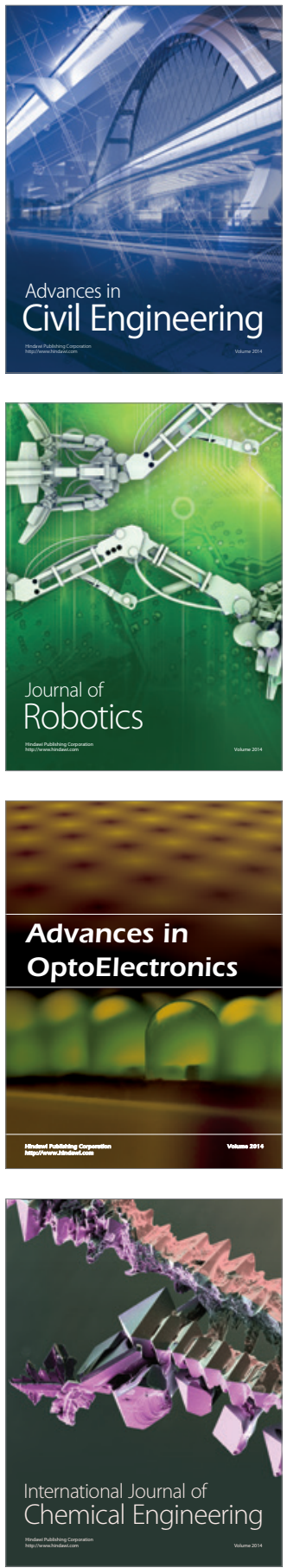

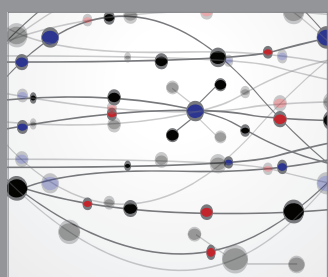

The Scientific World Journal

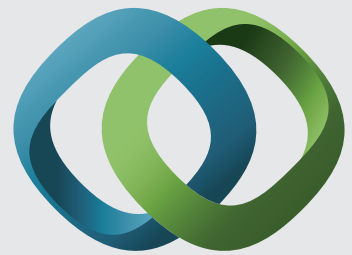

\section{Hindawi}

Submit your manuscripts at

http://www.hindawi.com
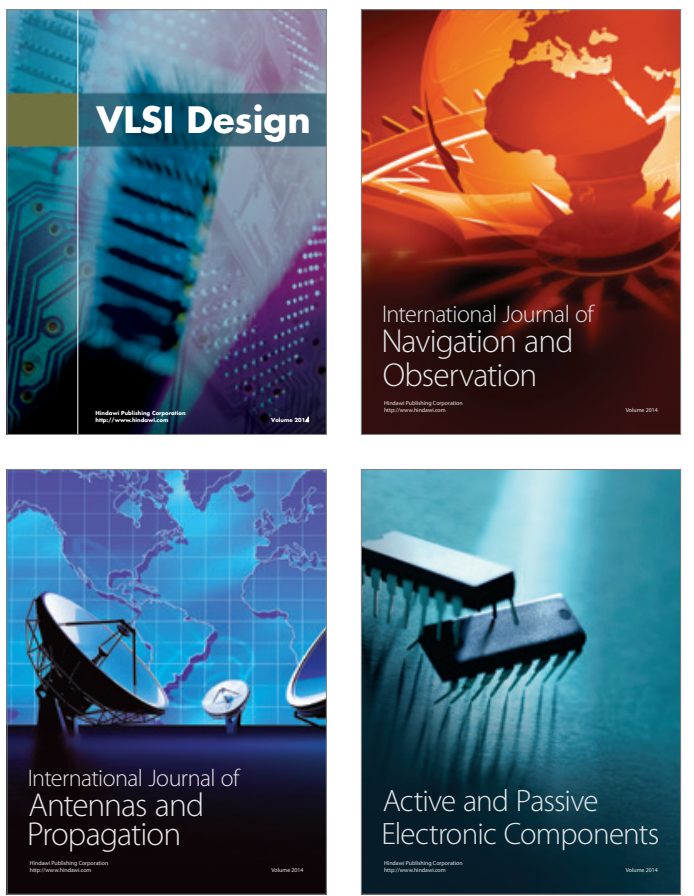
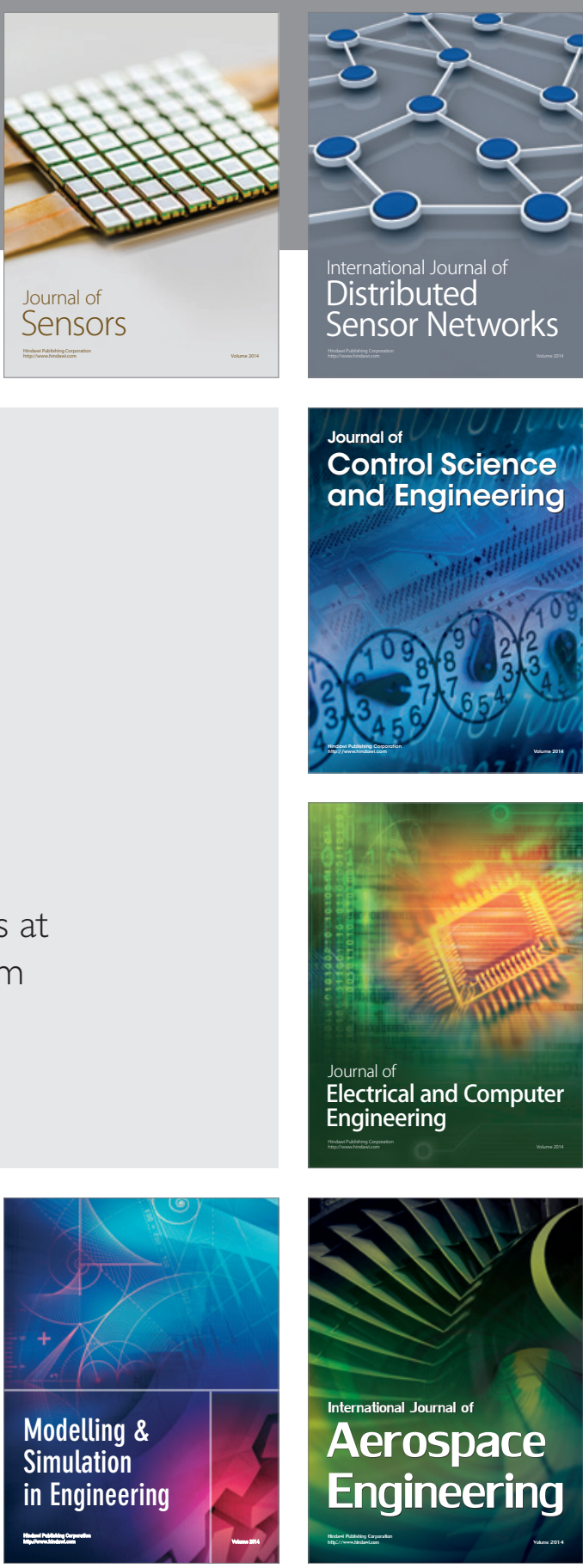

International Journal of

Distributed

Sensor Networks

Journal of

Control Science

and Engineering
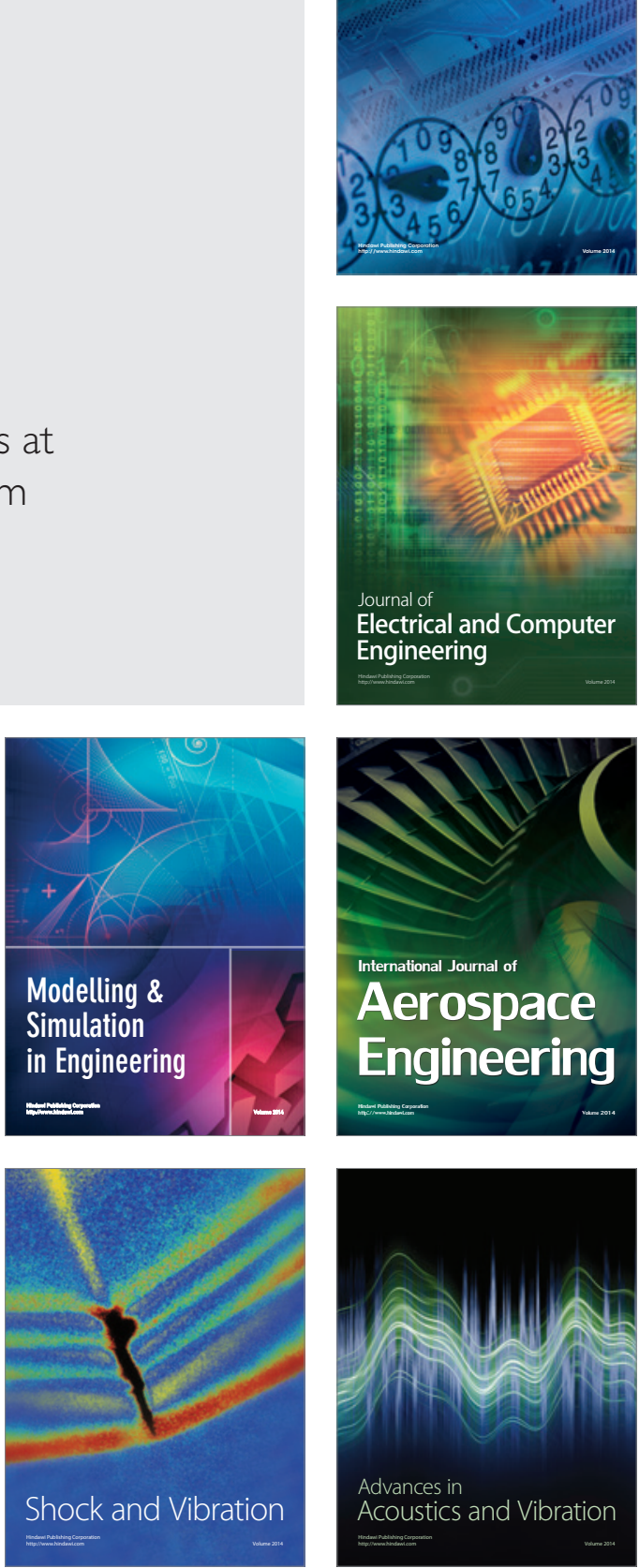